\title{
PENGARUH TEMPO MUSIK TERHADAP JUMLAH PENGUNJUNG, LAMA BERBELANJA, DAN VOLUME PEMBELIAN
}

\author{
Sutino Haliman \\ Haryanto F. Rosyid \\ Universitas Gadjah Mada
}

\section{INTISARI}

Penelitian eksperlmental ini bermaksud menguji hipotesis yang berkenaan dengan pengaruh tempo musik yang diperdengarkan di toko terhadap jumlah pengunjung, lama waktu berbelanja can volume pembelian yang dilakukan konsumen. Jenis musik yang dipergunakan dalam eksperimen ditetapkan musik yang bertempo cepat dan musik dengan tempo lambat.

Penentuan tempo musik dipercayakan kepada seorang ahlipakar musik dari institut Seni indonesia (ISi) untuk menjamin kualitas yang tepat. Jenis musik yang digunakan permainan piano instrumentalia. Pelaksanaan penelitian dilakukan of sebuat toko pakalan jadi yang sudah mempunyai segmen pasar tertentu.

Eksperimen dilaksanakan selama dua belas hari kerja dengan waktu berselang-seling, antara siang malam, dengan musik tempo cepal dan musik tempo lambat.

Hasil penelitian menunjukkan bahwa jumlah pengunjung yang memasuki toko tidak terpengaruh oleh jenis musik ( $t=0,734 ; p>0,05)$, sedang lama belanja dan besamya volume pembelian dipengaruhi secara signifikan oleh jenis musik yang diperdengarkan selama kunjungan konsumen, masing-masing secara berturutan dengan $1=2,577 ; p<0,05$ dan $t=2,242 ; \beta<0,05$.

Kata Kunci: Tempo musik, metronom, segmen pasar

Sutino Haliman, adalah alumnus Fakultas Psikologi UGM Yogyakanta.

Drs. Haryanto F. Rosyid, MA adalah dosen tetap Fakultas Pslkologi UGM. Meminati masalah-masalah pemasaran.

\section{LATAF BELAKANG}

1. usik merupakan suatu hasil seni $\Lambda$ budaya yang berupa unsur-unsur suara atau bunyi yang teratur sehingga terjadi suatu harmoni yang dapat memuaskan pendengarnya. Musik telah lama hadir di dalam kehidupan manusia, bahkan boleh dibilang manusia tidak dapat melepaskan diri dari musik di manapun ia berada. Musik 
telah menjadi bagian dari kehidupan manusia, yang dalam perkembangannya tidak saja menjadi media hiburan, tetapl musik telah mempunyai fungsi yang amat kompleks.

Dalam dunia industri, musik dipakai sebagai suara latar d tempat produksi agar hasi kerja mencapai tingkat optimal. Kantor dan toko juga menggunakan musik untuk menghasilkan sikap atau tingkah laku tertentu pada karyawan atau pelanggan. Sebagai contoh latar belakang musik digunakan untuk meningkatkan gengsi toko, membuat pekerja lebih gembira, mengurangi perputaran karyawan, dan menstimulasi pembeli.

Penelitian ini bertujuan untuk mengungkap pengaruh tempo musik cepat dan lambat terhadap jumlah pengunjung, lama berbelanja d toko, dan volume pembelian yang dilakukan oleh konsumen.

\section{DASAR TEORI}

Dalam proses pengambilan keputusan, konsumen akan melalui lima tahap berikut (Engel, Blackwell dan Miniard, 1990) (1) mengetahul akan adanya kebutuhan, (2) mencari informasi yang berkaitan dengan pemuas Kebutuhan tersebut baik dari informasi yang sudah ada pada dirinya (i. m- $^{-}$ ternal search) maupun dari lingkungannya (external search) (3) mengevaluasi atternatif atau mempersempit pilihan, (4) membeli pilihannya, dan (5) mengevaluasi pilihan yang telah dllakukan apakah sesuai dengan kebutuhan. Jumlah pengunjung, lama berbelanja dan volume pembelian merupakan bagian dari perilaku yang tampak. Perilaku ini dapat diamati melalui kegiatan yang dilakukan pelanggan, dan merupakan manifestasi dari perilaku tidak tampak, yang meru pakan proses yang terjadi di dalam diri individu yang berbelanja.
Pengubahan sikapdan perliaku konsumen sebagal tujuan dari pemasaran adalah hal yang biasa. Musik mempunyai peranan d sini karena musik mampu menj̧adi alat untuk membentuk perilaku konsumen. Di dalam toko banyak elemen yang clapat menjadi pendorong pembelian barang. Salah satunya berupa musik yang dihadirkan $d$ toko tersebut. Suasana hati dapat diciptakan atau dapat dimanipulasi dengan menggunakan musik. Seorang yang merasa santai mempunyaj kemungkinan yang lebih besar dalam melakukan pembelian.

Sebuah toko mempunyai banyak dimensi yang dapat dikontrol agar toko tersebut dapat menarik perhatian pembeli. Salah satunya adalah suasana toko terse but. Belk (1975) menyatakan ada beberapa karakteristik situasional yang mempengaruhi konsumen, yaltu: kondisi fisik di dalam toko, misalnya: lokasigeografis, dekorasl, suara, aroma, pencahayaan, cuaca, konfigurasi barang dagangan yang terlihat atau hal-hal yang dapat menjadi objek; kondisi soslal sekitar, misalnya kehadiran atau ketidak hadiran orang dalam situasi yang dihadapi; waktu, yaitu saat-saat perilaku membeli harus dilakukan; tugas atau tujuan khusus yang dimiliki konsumen dalam satu situasi (mlsalnya: ulang tahun, hadiah kejutan); serta kondisi sesaat, d mana suasana hati yang bersłat sementara menguasai konsumen, misalnya: rasa cemas, tidak membawa uang tunal, atau kondisil lelah fisik.

Lingkungan toko adalah hal-hal fisik dari sebuah toko yang dapat dirasakan oleh konsumen. Kotler (1974) menandaskan bahwa hal ini amat penting bagi seorang pemasar urtuk diketahui karena mengandung dua alasan: pertama, hal-hal fisik dapat dikontrol atau diubah-ubah untuk mendapatkan lingkungan toko yang baik, bukannya tidak dapat dikontrol seperti pengaruh situasional; kedua, pengaruhnya dapat tepat dirasakan langsung oleh konsumen d dalam 
toko. Seorang pemasar harus melihat lingkungan atau sítuasi toko sebagai suatu yang mempunyai efek pada konsumen. Lingkungan toko juga dapat menyatakan berbagal aspek dari toko kepada konsumen. Pengaturan toko yang baik dapat membangkitkan reaksi emosional tertentu pada dirl konsumen, misalnya emosi senang dan menggairahkan. Penelitian Kotler (1974) menunjukkan bahwa perasaan demikian dapa mempengaruhi jumlah waktu dan uang yang dibelanjakan konsumen pada saat berbelanja.

Lingkungan toko terdiri dari banyak faktor, dari ruang, penempatan, dan bentuk olsplayyang disajikan, warna, pencahayaan, ada tidaknya musik dalam toko, aroma, sampal pada temperatur yang sejuk dan nyaman di toko tersebut.

Beberapa hasll penelitian menunjukkan bahwa musik mempengaruhi perilaku konsumen. Studi awal yang dilakukan oieh Smith dan ,Curnov (1966) menunjukkan adanya pengaruh volume musik yang diperdengarkan d suatu toko serba ada (supermarket)terhadap pembelian. Konsumen menghabiskan waktu yang lebih singkat di dalam toko jika diperdengarkan musik yang bervolume keras, namun menghabiskan jumlah uang yang relat if sama dibandingkan dengan lagu dengan volume yang lebh kecil. Studi lain hasilnya menunjukkan adanya efek tempo musik (cepat dan lambat) terhadap perilaku pembeli d toko serha ada. Musik yang bertempo lambat lebih meningkatkan bak jumiah uang maupun jumlah waktu yang dihabiskan oleh konsumen dari pada yang menggunakan musik tempo cepat (Milliman, 1982). Pada waktu tempo lambat diperdengarkan d toko serba ada, langkah pengunjung toko secara tidak sadar menyesuaikan tempo tersebut dan menjadi leblh lambat. Hal ini sesuai dengan hukum resonansi d mana pendengar menyesuaikan gerakannya dengan tempo yang didengarnya (Motte-Haber, 1987). Dengan langkah yang lebih lambat ini, pengunjung menghabiskan waktu lebih lama yang tentu berakibat kemungkinan pembelian lebih besar.

Hasi serupa diperoleh melalui observasi yang dilaksanakan d rumah makan. Musik yang bertempo lambat meningkatkan jumlah konsumsi $50 \%$ dan menghabiskan waktu $25 \%$ lebih panjang dari pada dengan menggunakan muslk bertempo yang cepat (Milliman, 1986).

Sebagaimana membangun suatu rumah, musik juga memliiki bahan-bahan dasar untuk membuat suatu komposisi musik yang indah. Suatu komposisi musik yang baik amat ditentukan oleh keseraslan dan keterpaduan elemen dasar ini. Bahanbahan dasartersebut lalah: nada, elemenelemen waktu, melodl, harmoni \& tonalitas, tekstur, dan dinamika (Miller, 1970).

Tempo musik biasanya diukur dari jumlah ketukan dalam satu menit; makin banyak ketukan dalam satu menit maka dikatakan tempo musklk itu makin cepat dan makin sedikit ketukan dalam satu menit maka dikatakan tempo musik itu lambat. Untuk mengetahui kecepatan ketukan suatu lagu dapat digunakan alat yang disebut metronom. Tempo lagu kebanyakan ditulis dalam bahasa Italia. Istilah asing tersebut ditulis dari tempo paling lambat $40-43$ ketukan dalam semenit sampal ke yang paling cepat, dengan leblh 184 ketukan per menitnya (Soerjadi, 1977).

Berdasar teori musik di atas maka peneliti membedakan musik tempo cepat dan tempo lambat. Mulal darl Allegro, yaitu 116 ketukan per menit ke atas akan dikategonikan sebagai tempo cepat. Sedangkan tempo dari Andante yaltu 65 ketukan ke bawah akan dikategorikan sebagal musk tempo lambat. Sementara muslk dalam tempo Andantino sampal dengan Allegretto (66 - 115 ketukan per menit) tidak di- 
masukkan karena ada of antara keduanya, dimana sulit untuk dikategorikan apakah ketukan tersebuttermasuk cepat atau lambat.

Berdasar tinjauan pustaka yang telah dikemukakan, dapat ditarik kesimpulan bahwa penggunaan musik dapat mempengaruhidan memacutimbulnya pembelian. Musik dalam tempo yang cepat mempunyal kecenderungan memacu aktivitas seseorang menjadi leblh sigap, cepat, dan membangkitkan gairah mengikuti tempo musik yang disajkan tersebut. Sedangkan musik dengan tempo yang lambat akan berkecenderungan memperlambat perilaku orang yang mendengarnya. Pengetahuan ini tentu saja amat berarti bagi pemilik toko dalam pemilihan jenis tempo musik untuk diperdengarkan di tokonya.

Hipotesis yang akan diuji dalam penelitian ini lalah: jumlah pengunjung toko lebih banyak dengan menggunakan musik tempo cepat dari pada dengan musik tempo lambat; pengunjung menghabiskan waktu lebih banyak pada musik tempo lambat dibanding tempo cepat; jumlah pembelian lebih banyak dengan musik tempo lambat dibanding tempo cepat.

\section{METODE PENELITIAN}

Penelitian yang bersifat eksperimen ini menggunakan variabel independen tempo musik, yang terdiri atas: musik tempo cepat dan musiktempo lambat, varbel dependennya adalah: jumlah pengunjung, lama berbelanja, dan volume pembelian.

Tempo musik menunjukkan kecepatan gerak musik. Musik dapat bergerak dalam kecepatan yang sangat cepat, sedang, atau lambat, serta dalam berbagai-bagai tingKatan di antara kecepatan itu. Tempo musik (cepat atau lambat) dibedakan dengan menggunakan jumlah ketukan per menit. Dikatakan cepat jika ketukan lebih dari atau sama dengan 116 per menit (allegro), dan dikatakan lam bat jka kurang dari atau sama dengan 65 ketukan per menit (andante).

Jumlah pengunjung adalah banyaknya orang yang datang ke toko tempat eksperimen dilaksanakan. Seseorang dikatakan sebagai pengunjung toko apabila orang tersebut melalui/melewati ambang pintu toko dan menunjukkan minat untuk melihat pakaian yang dijual. Bilamana seseorang tidak melalui ambang pintu toko, tetapi menunjukkan minat dengan memeriksa pakaian yang ditawarkan pada bagian tengah toko yang sejajar dengan ambang pintu, maka orang tersebut dihitung sebagal seorang pengunjung toko.

Lama berbelanja lalah jumlah waktu yang pengunjung habiskan/lewatkan of toko tersebut yang dihitung dalam bilangan detik.

Volume pembelian adalah jumlah penjualan selama eksperimen (dua jam siang dan duajam malam) yang dicatat dari catatan kasir.

Agar hasil penelitian merupakan akibat dari perlakuan, dan bukan karena pengaruh faktor yang di luar kendali peneliti, maka ada beberapa hal yang perlu diperhatikan. Hal-hal yang dimaksud antara lain promosi. Promosi lalah segala macam kegiatan yang diupayakan untuk menarik perhatian konsumen untuk melakukan pembelian, misal discount, hadiah, atau kupon. Se lama penelitlan dilaksanakan, tidak boleh ada kegatan promosi karena akan mempengaruhi data eksperimen yang akan diperoleh. Orang membeli bukan karena efek tempo musik tetapi Karena adanya promosi (Business Week, 1986). Tata nuang (Iayout) toko yaitu susunan dan tata letak dalam toko yang bersangkutan. Susunan ini dipertahankan untuk terus selalu sama selama perlakuan. Bilamana letak pakaianjeans di dekat kasir, maka ia akan tetap d sana sampai semua perlakuan selesal (Engel, dkk. 1990). Suasana atau kondisi toko, yaitu hal-hal yang menyangkut kenyamanan toko. Ini 
meliputi warna, suhu, sirkulasi udara, pencahayaan dan lain-lain (Kotler, 1974). Hari besaryang berakibat pembelian yaitu tanggaltanggal yang membuat orang mempunyai kecenderungan untuk membeli, misalnya: pada hari-hari menjelang hari raya Tanggaltanggal demikian akan dihlndarkan karena akan menciptakan bias dalam data hasil eksperimen (Milliman, 1986). Sikap pramuniaga, yaitu sikap yang ditampilkan oleh pelayan toko yang melayanl konsumen pada waktu perlakuan. Untuk penelitian ini, para pramuniaga diusahakan untuk mempunyal sikap yang selalu konsisten. Dalam hal Inl pramuniaga tidak diberi tahu adanya penelitian dimaksud (Milliman, 1984). Jents musik yaitu macam musik yang dlsajkkan dan dalam konteks penelitian ini digunakan hanya satu jenls musik yaitu piano dengan iringan orkes. Hal inl dilakukan karena jen is musik memperngaruhi perilaku konsumen (Milliman, 1986).

\section{PELAKSANAAN EKSPEAIMEN}

Guna menjamln terlaksananya eksperimen, maka peneliti memlnta kepada pemilik toko agar tidak melakukan perubahan. apapun selama penelitian dilakukan. Eksperimen dilaksanakan di sebuah toko di pusat kota, yang menjual pakalan jadi, dlrilal sudah cukup mapan, stabil, dan telah memillkl segmen pasartersendirl.

Sebagal bagian dari persiapan yang haus dirancang secara masak lalah pengaturan sistem audio yang dipasang di toko, agar lagu-lagu yang dperdengarkan dapat dirasakan atau dirikmati oleh konsumen dengan nyaman

Setiap hari dilakukan eksperimen selama 4 (empat) jam yang dibagl menjadi dua, yaitu pada jam 10.00 - 12.00 untuk eksperlmen siang, dan 18.30-20.30 untuk waktu malam harl. Pada mlnggu pertama hari pertama, siang hari diberi musik tempo lambat dan malamnya tempo cepat, hari kedua siang tempo cepat dan malamnya tempo lambat, hari ketiga siang tempo lambat dar malamnya tempo cepat, demikian seaterusnya musik diberikan secara bergilir dari hari ke hari. Sedangkan pada minggu kedua hari pertama siang diputar lagu dengan tempo cepat dan malamnya tempo lambat, hari kedua siang tempo lam bat dan malamnya tempo cepat, dan seterusnya secara bergantian sampai selesai. Pelaksanaan penelitian dilakukan dalam waktu dua minggu atau dua belas hari kerja.

Musik yang dipergunakan dalam peneltlan ini lalah musik piano Richard Clayderman dengan iringan orkes. Lagulagu yang dipergunakan diambil dari Rich ard Clayderman Complete Edition. Musik yang dlgunakan ini hanya dalam bentuk instrumental yang didominasl piano. Hal in penting untuk mengontrol kemungkinan pengaruh vokal manusia pria dan wanita atau artls populer dengan artis yang tidak populer. Lagu-lagu Richard Clayderman pertama-tama diseleksl berdasar blramanya. Peneliti hanya mengamb\|l lagu-lagu dengan birama $4 / 4$ (empat per empat). Lagu-lagu berbirama $4 / 4$ ini kemudian diseleksi yang mempunyai tempo lebih cepat atau sama dengan 116 ketukan per menit dan yang lebih lambat atau sama dengan $\bar{\delta}$ ketukan per men it Untuk menyeleksi jenis lagu yang dipergunakan dalam penelitian ini, peneliti meminta jasa bantuan darl seorang pakar musik darl ISI (Institut Senl Indonesia) Yogyakarta. Kritteria yang dljadikan penilalan lalah nada, elemen waktu, melodi, harmoni, tekstur, dan dinamika. Sebagaimana penelitian Smith dan Curnow (1966) menunjukkan bahwa volume musik berpengaruh terhadap perilaku konsumen, maka dalam hal ini volume musik yang diperdengarkan dikendalikan untuk tetap sama. 


\section{HASIL DAN PEMBAHASAN}

Hasil perhitungan yang didapatkan selama penelitian tergambar dalam tabel berikut ini:

Tabel 1

\section{Deskripsi Data Penelitian}

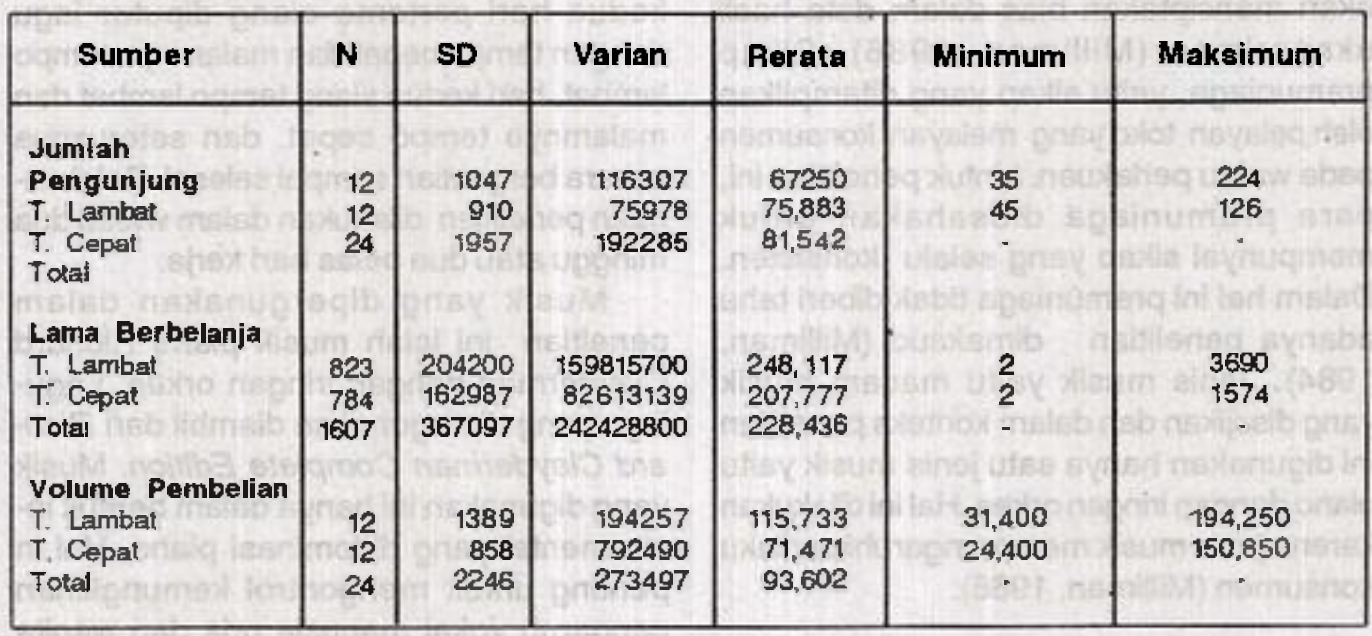

Berdasar hasil analisis uji t (t-test) ternyata tidak ada peibedaan yang signifikan antarajumlah pengunjung toko pada musik tempo lambat dengan musik tempo cepat $(t=0,734 ; p>0,05)$. Maka hipotesis 1 yang diajukan dalam penelitian ini tidak dapat diterima.

\section{Tabel2}

Hasil Analisis Uji t

\begin{tabular}{|l|c|c|}
\hline \multicolumn{1}{|c|}{ Sumber } & $t$ & $p$ \\
\hline $\begin{array}{l}\text { Jumlah Pengunjung } \\
\text { T. Lambat-T. Cepat } \\
\text { Lama Berbelanja }\end{array}$ & 0,737 & $>0,05$ \\
$\begin{array}{l}\text { T. Lambat-T. Cepat } \\
\text { Volume Pembelian }\end{array}$ & 2,577 & $<0,05$ \\
T. Lambat- $T$. Cepat & 2,242 & $<0,05$ \\
\hline
\end{tabular}


Berdasar hasil analis/s, ternyata ada perbedaan yang signifikan antara lama berbelanja konsumen pada musik tempo lambat dan musik tempo cepat $(t=2,577$; $p<0,05)$. Kesimpulan yang dapat ditarik ialah menerlma hipotesis kedua, yaitu dengan memperhatikan hasll rerata, maka musik tempo lambat ternyata membuat konsumen berbelanja lebih lama (mean $=248,117$ detik) dibandlngkan dengan lama belanja pada waktu diperdengarkan musik tempo cepat (mean $=207,777$ detik).

Berdasartampilan analisis, ternyata ada perbedaan yang signifikan antara volume pembelian konsumen pada musik tempo lambat dan musik tempo cepat $(t=2,242$; $<0,05)$. Kesimpulan ini berarti menerima hipotesis ketlga, yang juga menunjukkan bahwa musik tempo lambat membuat volume pembelian konsumen leblh besar (mean = Rp. 115.733,00) dibandingkan volume pembelian yang dilakukan pada saat diperdengarkan musik tempo cepat (mean= Rip. $71.471,00$ )

Pembahasan yang dapat dilakukan menyangkut jumlah pengunjung yang tidak berbeda karena tempo musikyang berbeda dapat dijelaskan dengan teori perhatian (McMohan dan McMohan, 1986; Benjamin, dkk, 1987). Sesuatu akan ciperhatikan tergantung pada dua faktor, yaitu: faktor personal, dan faktor stimulus (Engei, dkk. 1990). Faktor personal meliputi kebutuhan/ motivasi, sikap, tingkat adaptasi, dan rentang perhatiannya. Sedangkan faktor stimulus meliputi ukuran, warna, intensitas, kontras, posisi, arah, gerakan, isolasi, kejanggalan, stimulus yang dlkenal, pembicara yang menarik, dan perubahan.

Dalam konteks hasil eksperimen ini, dua faktor tersebut memberikan kontribusinya. Calon konsumen sudah masuk dalam tIngkat adaptasinya terhadap musik. Sepanjang pertokoan tempat eksperimen dilakukan, dapat didengarkan musikdengan jenis dan tempo yang beragam. Calon konsumen sudah menjadi terblasa (beradaptasi) dengan musik tersebut sehingga tidak lagi memberikan perhatian.

Dari faktor stimulus, sudah tidak mampu memberikan kontras atau Intensitas yang kuat untuk menarik perhatian calon kosumen. Hal ini disababkan suasana sekitar toko yang tldak memungkinkan. Toko lain sudah memasang perangkat audio dengan suara keras, jika toko tempat penelitian akan memperkeras, justru akan menimbulkan gangguan pendengaran konsumen karena sudah of atas ambang pendengaran yang nyaman.

Untuk toko pakaian, seperti tempat penelitlan inl, ada beberapa tahap yang dilalul eaion konsumen sampal betul-betul melakukan pembelian. Tahap-tahap tersebut dikenal dengan sebutan AIDA atau Awareness, Interest, Desire, dan Action (McCarthy, 1984; Engel, 1990). Penjelasan dapat diberikan mengapa musik di dalam toko mampu mempengaruhi perilaku konsumen. Jika konsumen sudah masuk dalam toko, perhatian yang harus dilakukan oleh konsumen sudah berkurang (relatif lebih sedikit) daripada berada di luar toko. Salah satu yang dengan tidak disengaja atau sengaja diperhatikan adalah alunan musik tersebut. Dalam toko musk yang terdengar hanya satu, tidak campur aduk (jenis lagu, copat-lambat, dan laln-laTn) seperti di luar toko sehingga konsumen tidak ada pilihan lain terhadap lagu yang disalikan. Suasana dalam toko lebih tenang dari pada di luar toko (sepanjang kaki lima) sehingga orang jauh lebih bisa menikmati suasana.

Proses psikologls yang menyertai dapat djjelaskan dengan hukum fisika tentang gelombang resonansi (Motte-Haber, 1987). Hukum resonansi Ini mengatakan bahwa jka ada dua gelombang atau lebih yang berbeda frekuensi bertemu, maka akan terjadi saling menyesuaikan. Tempo yang lambat atau 
cepat dari musik yang sedang diputar tidak dapat berubah karena sifat mekaniknya. Manusia atau konsumen yang mendengarkan musik tersebut secara tidak sadar mengkuti gelombang suara tersebut. Konsumen yang mendengarkan suara tersebut jika sengaja tidak mau mengikuti gelombang tersebut akan merasa tidak nyaman.

Lama berbelanja konsumen di toko memillki kecenderungan menaikkan volume pembellan yang terjadi. Jika calon konsumen menghabiskan waktu lebih banyak dalam suatu toko, ada kecenderungan subjek melihat lebih banyak hal yang ditawarkan (Milliman, 1982). Tempo lambat membuat konsumen merasa lebih santai dalam berbelanja (Honegger, 1987). Faktor-faktorinilah yang mendorong konsumen melakukan pembelian barang (pakaian) yang ditawarkan.

\section{SIMPULAN}

Hasil eksperimen yang dilakukan menunjukkan ada perbedaan yang signifikan antara lama berbelanja konsumen dengan musik tempo lambat dan musik tempo cepat. Tempo lambat membuat konsumen menghabiskan waktu berbelanja lebih lama. Hasil lain memperlihatkan perbedaan yang signifikan dalam volume pembelian antara musik dengan tempo lambat dan musik dengan tempo cepat. Musik tempo lambat membuat volume pembelian lebih besar dibandingkan dengan musik tempo cepat. Hasil penelitian juga manunjukkan tidak adanya perbedaan yang signifikan antara musik tempo lambat dan musik tempo cepat dalam mempengaruhi jumlah pengunjung toko.

Dari penelian ini dapat dikemukakan saran yang berkaitan dengan jenis musik yang dipergunakan. Jenis musk yang dimaksud misalnya musik populer, keroncong, irama melayu (ndang-dut), atau bila ingin diketahui pengaruhnya sajkkan musik rock.
Sementara berkaitan dengan tempat pelaksanaan eksperimen, dapat dilakukan d jenis usaha yang lain, selain toko, misalnya: restoran, toko buku, toko perhiasan.e

\section{DAFTAR PUSTAKA}

Benjamin, L.T., Hopkins, J.R, dan Nation, J.R. 1987. Psychology. New York: Macmillan Publishing Company.

Business week. 1986. How Pontiac Pulled Away from The Pack. 25 Agustus 1986, 56-57.

Engel, J.F., Blackwell, R.D., dan Miniard, P.W. 1990. Consumer Behaviour. (6th edt.) Orlando: The Dryden Press.

Engel, LJ.F., Kollat, D.T., \& Blackwell, R. D. 1973. Consumer Behaviour. (2nd. edt.) Hinsdale, Ilinois: The Dyden Press.

Honneger, M. 1987. Das Grosse Lexikon Der Musik(vol. 5). Freiburg: Herder.

Kotler, P. 1974. Atmospherics as a Marketing Tool. Journal of Retailing. 49, 48-65.

Kotler, P. 1988. Marketing Management: Analysis, Planning, Implementation, and Contrtol(Gth ect) Englewood Cliffs, New Jersey: Prentice Hall Inc.

McCarthy, E. J. \& Perreault, W. D. 1984. Basic Marketing: A Managerial Approach. (8th edt.) Homewood: Richard D. Irwin, he.

McMohan, F.R., \& McMohan, J.W. 1986. Psychology: The Hybrid Science. (5th edt). Chicago, llinois: The Dorsey Press.

Miler, H.M. 1970. Introduction to Music: $A$ GuidetoGoodListening. Tokyo: McGrawHill Kogakusha, Ltd. 
Milliman, R.E. 1982. Using Background Music to Affect the Behavior of Supermarket Shopper. Journal of Marketing. 46, 86-91.

1986. The Influence of Background Music on the Behavior of Restaurant Patrons. Journal of Consumer Research. 13. 286-289.

Moskowitz, M. J. \& Orgel, A.R. 1970. General Psychology. Hlinois: Houghton Mifflin.
Motte-Haber, H.D. 1987. Musikpsychologie. Freiburg: Herder.

Soerjadi. 1977. Kamus Kecil Istilah-istilah Musik. Jakarta: Pantja Simpatl.

Swastha, B. \& Handoko, H. 1987. Manajemen Pemasaran: Analisis Perllaku Konsumen. Yogyakarta: Penerbit Liberty.

Wellek, A. 1963. Musikpsychologie und Musikasthelik. Frankfurt: Akademische Verlags Gesellschaft.

Ucapan terima kasih khusus penulis sampaikan kepada Drs. Suglyanto, Ph. D. Fakultas Psikologi UGM, al as final revisw yang dilakukan untuk naskah ini 